\title{
Clasificación y caracterización de los bancales de la provincia de Ávila
}

\author{
Classification and Characterization of the Stone Terraces of Ávila \\ Province
}

\author{
Jorge Mongil Manso* \\ Universidad Católica de Ávila \\ https://orcid.org/0000-0003-2699-7585 \\ jorge.mongil@ucavila.es \\ Joaquín Navarro Hevia \\ Universidad de Valladolid \\ https://orcid.org/0000-0002-3759-8662 \\ joaquin.navarro.hevia@uva.es \\ José Carlos Sanz Belloso \\ Profesional Independiente \\ https:/ / orcid.org/0000-0002-2652-6831 \\ jcsanzbelloso@gmail.com
}

Recibido: 28/06/2020; Revisado: 15/10/2020; Aceptado: 22/10/2020

\begin{abstract}
Resumen
Los bancales de la provincia de Ávila (España) constituyen un patrimonio histórico y tradicional que, por sus funciones y valores, merecen ser conocidos, conservados y divulgados. En este trabajo se realiza una primera aproximación a su conocimiento, estableciendo su distribución por municipios y comarcas, así como una clasificación diferentes tipos de bancales, con sus características específicas. Para ello, se han utilizado ortofotografías aéreas, imágenes de satélite y transectos. La superficie aterrazada en la provincia supera las 5.000 ha, concentrándose principalmente en las comarcas del Valle del Tiétar y Valle del Alberche y Pinares, habiéndose distinguido seis tipos diferentes de terrazas.
\end{abstract}

Palabras clave: Agrosistema, Castilla y León, conservación de suelos, paisaje, terrazas.

*Autor de correspondencia / Corresponding author.

Copyright: (c) 2021 ULPGC. Este es un artículo de acceso abierto distribuido bajo los términos de la licencia Creative Commons Atribución-NoComercial-SinDerivar (by-nc-nd) Spain 3.0. 


\begin{abstract}
The stone terraces of the province of Ávila in Spain constitute a historical and traditional heritage that deserves conservation and promotion in recognition of their function and value. This article represents an initial attempt at evaluating these stone terraces, recording their distribution within municipalities and regions, as well as classifying the different types of terraces with their specific characteristics. This has involved the use of aerial orthophotos, satellite images and field transects. The area of terraced land in the province is over 5000 ha, mainly concentrated in the regions of the Tiétar valley and the Alberche y Pinares valley, wherein six different types of stone terraces have been distinguished.
\end{abstract}

Key words: Agricultural Systems, Castilla y León, Landscaping, Soil Conservation, Stone Terraces.

\title{
1. INTRODUCCIÓN
}

Los bancales tradicionales de la provincia de Ávila (Castilla y León, España) configuran un paisaje agrícola con elevado valor ambiental, cultural y estético, que constituye un patrimonio a conservar. Estos sistemas de cultivo fueron diseñados, ejecutados y conservados por nuestros antepasados. Su origen en la Península Ibérica parece establecerse en la Edad de Bronce (2000 años a.C.), aunque los restos arqueológicos más antiguos son probablemente romanos (AsinsVELIS, 2006), y se estima que, en la Unión Europea, las terrazas de piedra agrícolas alcanzan una longitud de algo más de 1,7 millones de km (LASANTA et al., 2013). Actualmente, sufren en muchos casos un lamentable proceso de degradación. Pero no sólo deben ser conservados por sus valores culturales tradicionales, sino también porque actualmente son elementos de conservación de suelos y aguas y tienen un notable valor como paisajes culturales.

Por todo ello, es necesario abordar un estudio en profundidad que sirva para diagnosticar el estado de conservación de los bancales, desde el punto de vista de los valores aludidos. Aspectos fundamentales que analizar son el papel regulador del ciclo hidrológico de las vertientes, la calidad constructiva de los muros, las cualidades estéticas, el suelo generado que conservan, sus valores identitarios y la integración de las actuaciones humanas.

Los paisajes de terrazas son el resultado de un extenso proceso de transformación del medio natural, llevado a cabo por determinadas sociedades para abordar limitaciones físicas (topográficas, edáficas y climáticas) y obtener unos recursos imprescindibles para su supervivencia (ROMERO et al., 2016). Pueden considerarse como agrosistemas, en los que interaccionan algunos factores naturales tales como la pendiente, la litología, los suelos, la escorrentía o la infiltración, con otros de tipo socioeconómico como la población o la actividad económica. Las terrazas o bancales poseen un carácter plurifuncional y sostenible, tanto en su construcción (GROve y RackHAM, 2001; TAROLLI et al., 2014), como en manejo (SCARAMELLINI, 2005; LASANTA et al., 2011, 2013; ROMERO et al., 2004, 2006; ROMERO, 2015; VAROTTO, 2015; NORIYUKI, 2015). La productiva es su función más importante, siendo habitualmente fundamentales en el abastecimiento de alimentos y otros productos a los habitantes de zonas de montaña. Por otra parte, 
su función ambiental se plasma en una serie de servicios ecosistémicos como la creación de suelo fértil, la mejora de la infiltración, la recogida de agua, la conservación de suelos (controlando la erosión hídrica laminar, en regueros y los movimientos en masa) (TAROLLI et al., 2014), la prevención y extinción de incendios forestales (LOURENÇO y NAVE, 2007), su papel como reservas de biodiversidad (LASANTA et al., 2013), el cuidar y conservar uno de los bienes más preciados y escasos -el propio suelo mejorado históricamente-, o su interés paisajístico y estético. Así mismo, las terrazas o bancales son elementos de identidad cultural, de una cultura de subsistencia y de necesidad, de la escasez de suelos para el cultivo y de la economía del agua, en los que los constructores y usuarios han demostrado un profundo conocimiento del terreno y de las técnicas constructivas, especialmente de la construcción en mampostería de piedra seca (ROMERo et al., 2016). De cara al futuro, parece que cobrarán importancia el interés turístico y el papel científico de los bancales. Incluso no se puede ni debe descartar una nueva puesta en uso.

No obstante, en muchas zonas abancaladas del mundo el abandono masivo de estos espacios, a partir de la mitad del siglo xx, ha provocado su degradación y deterioro y pone en riesgo su supervivencia. Por ello, se han puesto en marcha diversos proyectos internacionales o locales, para fomentar su conservación, conocimiento y apreciación, entre los que destacan los desarrollados por la UNESCO o por la Alianza Internacional de Terrazas (ITLA).

Como en tantas otras regiones, los agricultores de la provincia de Ávila han utilizado desde tiempo inmemorial, y siguen haciéndolo, las terrazas y bancales. Estas estructuras de la agricultura tradicional se distribuyen por toda la provincia, aunque con significación y tipología diferentes (MongIL et al., 2015). Aunque es posible que con una tradición de proto-bancales en épocas anteriores, quizás los bancales comenzaron a extenderse en la provincia con el establecimiento de los visigodos. Éstos, en las tierras de montaña, utilizaban el abancalamiento como tierra de cultivo, para evitar la erosión, junto a los setos de vegetación (BALMASEDA, 2005).

Desde el punto de vista geomorfológico, la provincia se divide en dos grandes sectores. Por un lado, la parte más al norte pertenece a la cuenca sedimentaria del Duero, con un relieve suave de llanuras y lomas a unos 800-900 m de altitud, donde predominan materiales neógenos con arenas y lutitas, acompañados por formaciones cuaternarias generalmente asociados a depósitos fluviales o de terrazas, arenas eólicas, abanicos aluviales o coluviones. Por otra parte, en el sur de la provincia, correspondiente a la unidad montañosa del Sistema Central con altitudes de 1000 a $2600 \mathrm{~m}$, existe una alternancia de montañas y valles de los principales ríos, en un relieve de horts y grabens. Esta zona presenta un dominio de materiales magmáticos, fundamentalmente granitos y rocas afines, acompañados por algunos enclaves de rocas metamórficas. Con estos materiales geológicos aflorantes, los tres órdenes de suelos más representados en la provincia son los Entisoles, Inceptisoles y Alfisoles.

En general, puede describirse el clima de la provincia como mediterráneo continentalizado. Es mediterráneo en cuanto a las precipitaciones, con una marcada 
sequía estival. Y es continental en cuanto a las temperaturas, con inviernos largos y fríos, y veranos cortos y más o menos calurosos, según la altitud. La excepción es la parte meridional de la provincia, las comarcas del Valle del Tiétar y el Valle del Bajo Alberche, que posee un clima mediterráneo templado. En la zona norte, las precipitaciones rondan los $400 \mathrm{~mm}$ anuales; mientras que, en el sur, cae un promedio de 650-1300 mm en las zonas montañosas y de 1000-2000 $\mathrm{mm}$ en el valle del Tiétar (al sur de las principales elevaciones del sistema Central), comarca en la que son más abundantes los bancales.

El objetivo de este trabajo es realizar una primera aproximación al conocimiento de los bancales de la provincia de Ávila, en el marco del proyecto de investigación titulado «Los bancales de la provincia de Ávila. Un patrimonio rural tradicional a conservar» (TERRAV-I), estableciendo su distribución por municipios y comarcas, así como elaborar una clasificación de los diferentes tipos de bancales, con sus características propias. Este proyecto, financiado por la Institución Gran Duque de Alba de la Diputación de Ávila, pretende contribuir al conocimiento de los bancales de la provincia de Ávila, en cuanto a su distribución, características, tipología y funcionamiento como agrosistema, para valorizar este patrimonio rural y cultural tradicional y fomentar su conservación. Para ello, se han establecido los siguientes objetivos específicos:

- Cartografiar los paisajes de bancales, para conocer su distribución real en la provincia.

- Caracterizar los bancales en cuanto a su sistema y elementos constructivos, topografía, vegetación, suelos, etc.

- Establecer tipologías de bancales de la provincia de Ávila.

- Conocer algunos aspectos del funcionamiento de los bancales, tales como: retención de escorrentías, infiltración de agua en el suelo, almacenamiento del agua en el suelo, erosión, etc.

- Dar a conocer estos paisajes, valorar su interés para sensibilizar a sus poblaciones y a distintas comunidades (científicas, excursionistas, medioambientalistas, geológicas, paisajistas...).

- Establecer puntos débiles, perturbaciones, riesgos y problemas para la conservación del patrimonio rural tradicional que constituyen los bancales.

- Determinar las potencialidades de los bancales, así como posibles iniciativas para su conservación, en el marco de la agricultura y ganadería sostenibles, la etnografía y el turismo rural, así como de los problemas que afectan en la actualidad al medio rural de la provincia como son la despoblación, el cambio global, los incendios forestales y la gestión y conservación de los recursos naturales.

\section{METODOLOGÍA}

Se ha realizado un inventario de las áreas abancaladas de la provincia, mediante la utilización de fotografías aéreas delSIGPAC(2017) (Figura1), imágenes de satélite de Google Maps (2020) y el Mapa de Cultivos y Aprovechamientos (2000-2010) a través del Sistema de Información Geográfica Agraria (SIGA) del 
Ministerio de Agricultura, Pesca y Alimentación. La información recogida ha permitido elaborar un mapa provincial con la distribución de los bancales.

Posteriormente, con el objetivo de realizar una clasificación de los diferentes tipos de bancales, se ha llevado a cabo una serie de transectos por carreteras y caminos que atraviesan zonas aterrazadas, con recorridos prefijados. Para tal fin, se ha diseñado un estadillo específico, para recoger información sobre vegetación y cultivos, suelos, topografía, elementos y técnicas constructivas (materiales, tipos de mampostería, etc.). Los criterios para establecer la clasificación fueron: dimensiones, características constructivas y materiales empleados.

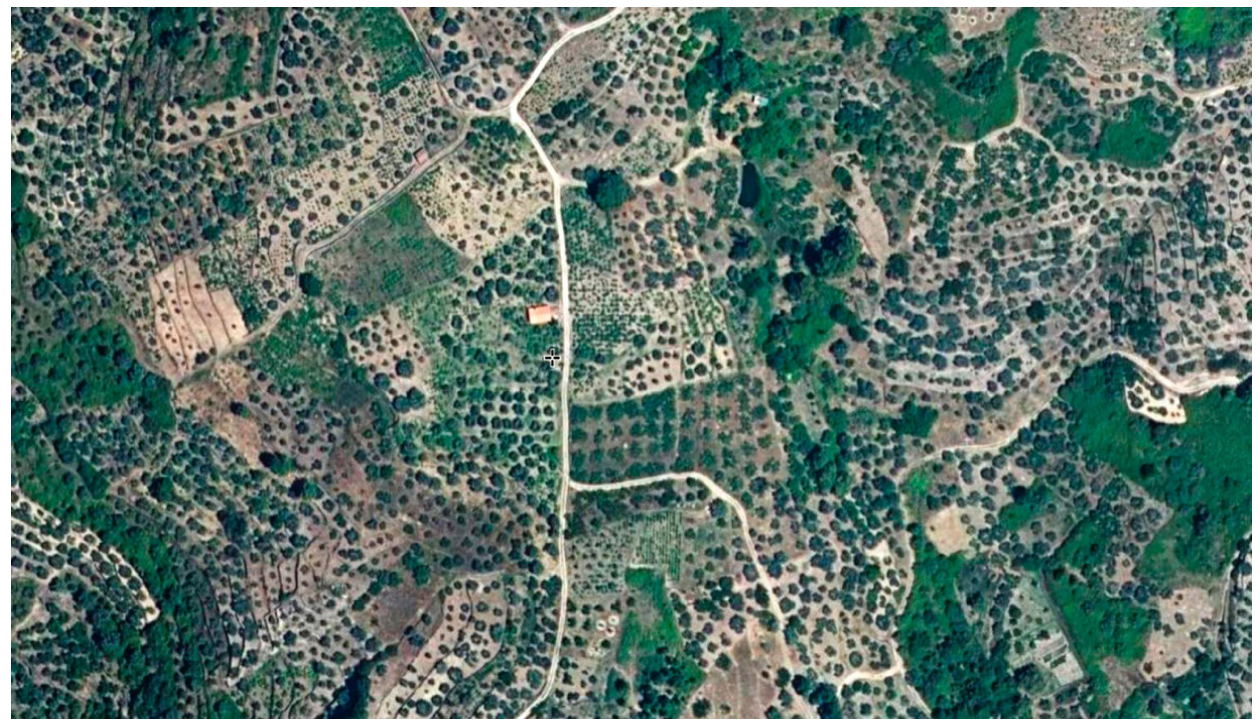

Figura 1. Fotografía aérea en Cuevas del Valle (Valle del Tiétar, Ávila), empleada en la delimitación de zonas abancaladas. Foto: SIGPAC.

\section{RESULTADOS Y DISCUSIÓN}

En el Mapa 1 se muestra el mapa provincial que permite observar la distribución de los bancales abulenses, por comarcas y municipios. Destaca la presencia de bancales en la comarca del Valle del Tiétar, con terrazas en casi todos los municipios, existiendo 15 municipios en los que los bancales son especialmente abundantes (Tabla 1). En una comarca donde una buena parte de la superficie está ocupada por bosque y matorral, la superficie abancalada supera las 5000 ha. En esta comarca, un 6,4\% de la superficie está abancalada, destacando Poyales del Hoyo donde los bancales alcanzan el 48\%. Arenas de San Pedro tiene el 21\% de los bancales de la comarca. 


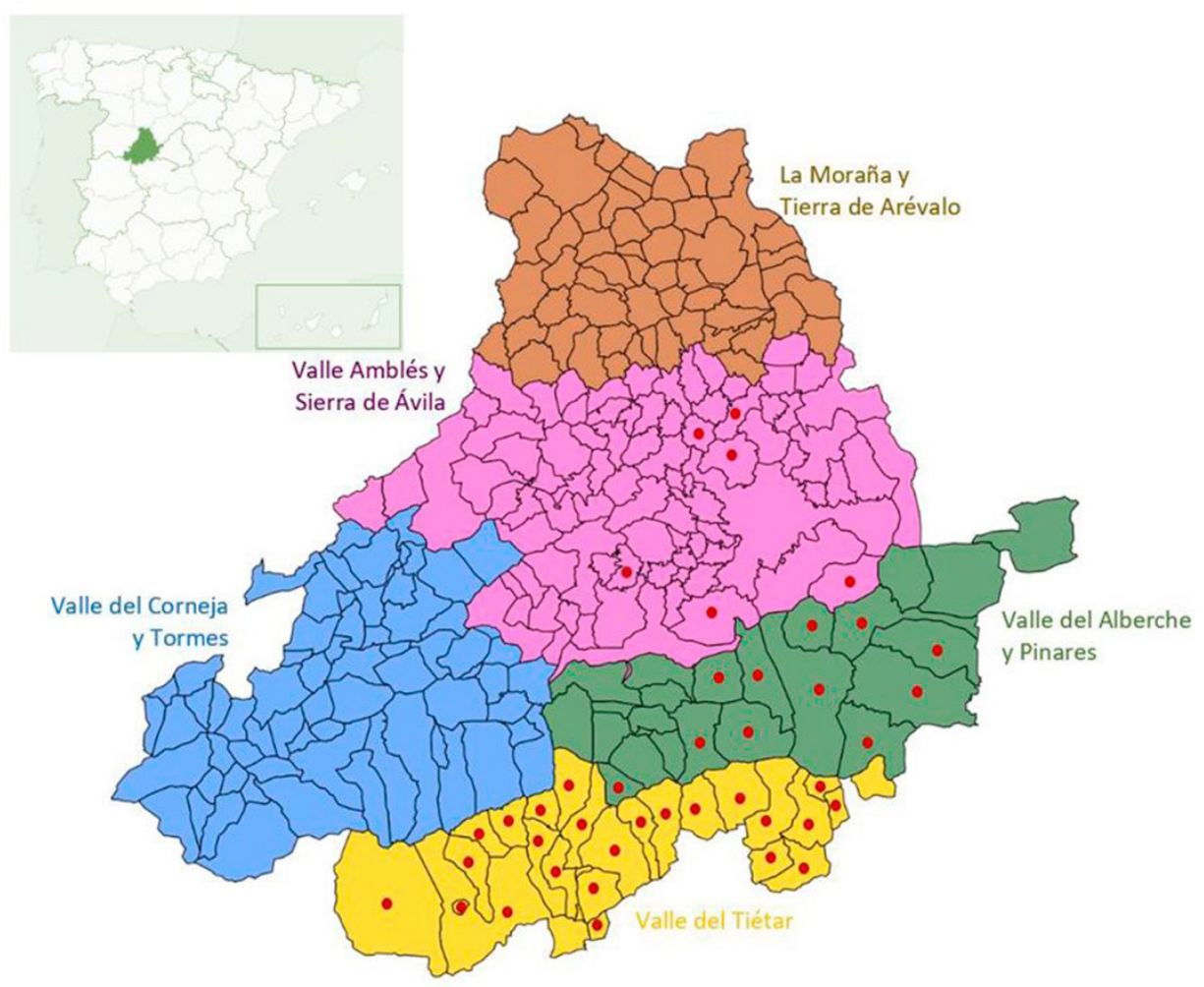

Mapa 1. Distribución de los bancales en la provincia de Ávila. En el mapa aparece la división en comarcas y municipios. Se han señalado con punto rojo aquellos municipios con superficie significativa de bancales ( $>2$ ha). Fuente: elaboración propia.

Otra comarca con bancales frecuentes es la del Valle del Alberche y Pinares, donde las terrazas están muy ligadas tradicionalmente al cultivo de la vid. En esta comarca la superficie abancalada ronda las 100 ha repartidas en 11 municipios.

Finalmente, son de destacar las terrazas de tierra, sin muros de mampostería, presentes principalmente en el término municipal de Peñalba de Ávila, al norte de la provincia, con unas 40 ha. 
Jorge Mongil Manso, Joaquín Navarro Hevia y José Carlos Sanz Belloso

TABLA 1

Distribución de la superficie de bancales en los quince municipios donde son más frecuentes, todos ellos situados en la comarca del Valle del Tiétar

\begin{tabular}{lcccc}
\hline \multicolumn{1}{c}{ Municipio } & $\begin{array}{c}\text { Superficie } \\
\text { total (ha) }\end{array}$ & $\begin{array}{c}\text { Superficie } \\
\text { bancales (ha) }\end{array}$ & $\begin{array}{c}\text { \% bancales } \\
\text { respecto total }\end{array}$ & $\begin{array}{c}\text { \% bancales } \\
\text { respecto total } \\
\text { comarca }\end{array}$ \\
\hline Villarejo Del Valle & 4156,69 & 185,12 & 4,45 & 3,40 \\
Santa Cruz Del Valle & 2960,46 & 180,25 & 6,09 & 3,31 \\
San Esteban Del Valle & 3700,25 & 430,3 & 11,63 & 7,89 \\
Poyales Del Hoyo & 335,31 & 161,88 & 48,28 & 2,97 \\
Piedralaves & 5524,1 & 181,93 & 3,29 & 3,34 \\
Pedro Bernardo & 6904,35 & 454,69 & 6,59 & 8,34 \\
Mombeltrán & 4992,34 & 413,61 & 8,28 & 7,59 \\
Lanzaita & 3363,4 & 256,35 & 7,62 & 4,70 \\
El Hornillo & 2414,35 & 153,99 & 6,38 & 2,82 \\
Guisando & 3732,67 & 155,66 & 4,17 & 2,85 \\
Gavilanes & 2113,71 & 149,52 & 7,07 & 2,74 \\
Cuevas Del Valle & 1919,35 & 151,08 & 5,57 & 2,77 \\
Candeleda & 21396,43 & 1069,23 & 5,00 & 19,61 \\
Arenas De San Pedro & 19468,87 & 1156,24 & 5,94 & 21,21 \\
El Arenal & 2710,03 & 352,53 & 13,01 & 6,47 \\
Total & 85692,31 & 5452,38 & 6,36 & $\mathbf{1 0 0 , 0 0}$ \\
\hline & & & & \\
\hline
\end{tabular}

Fuente: Elaboración propia.

De los transectos realizados, se han diferenciado seis tipos de terrazas o bancales. En la Tabla 2 se sintetizan sus principales características. Los seis tipos se describen a continuación:

1) Bancales tipo «Valle del Tiétar» (Figura 2). Es el tipo más abundante en la provincia y se localiza en la comarca del mismo nombre. Se trata de bancales típicos, con taludes verticales de 1-2 m de altura, recubiertos de piedra seca, en este caso bloques de granito, por ser la piedra local. La plataforma, o bancal propiamente dicho, es prácticamente horizontal o con una ligera pendiente y suele tener unos $5 \mathrm{~m}$ de anchura. Según la clasificación de López Cadenas (2003), son terrazas de base media, a nivel, de absorción y de piedra. Según la clasificación de Grove y Rackhman (2001), son terrazas ligurianas. No existe terreno sin alterar, es decir, en una misma ladera existe una sucesión continua de muros y plataformas. Se utilizan para el cultivo de olivos, castaños, vides, higueras y otros frutales.

2) Bancales tipo «Cebreros» (Figura 3). Los bancales de este tipo aparecen con frecuencia en la comarca del Valle del Alberche y Pinares, como en Cebreros, El 
Tiemblo, San Bartolomé de Pinares, Santa Cruz de Pinares, etc., siempre ligados al cultivo de la vid, puesto que este es el centro neurálgico de la Denominación de Origen Protegida «Vinos de Cebreros». Se construyen en laderas de fuertes pendientes, y tienen taludes de piedra seca (granito o esquisto) y de poca altura (menor de $1 \mathrm{~m}$ ), siguen curvas de nivel de forma continua o discontinua, no crean una plataforma horizontal sino inclinada, pero sí reducen la pendiente original de la ladera, especialmente en la zona más próxima al muro. Según la clasificación de Grove y Rackhman (2001) son, básicamente, terrazas ligurianas. Algunos de estos bancales han sido abandonados y dedicados a pastizales, como en El Herradón. Se estima una superficie de unas 100 ha de bancales.
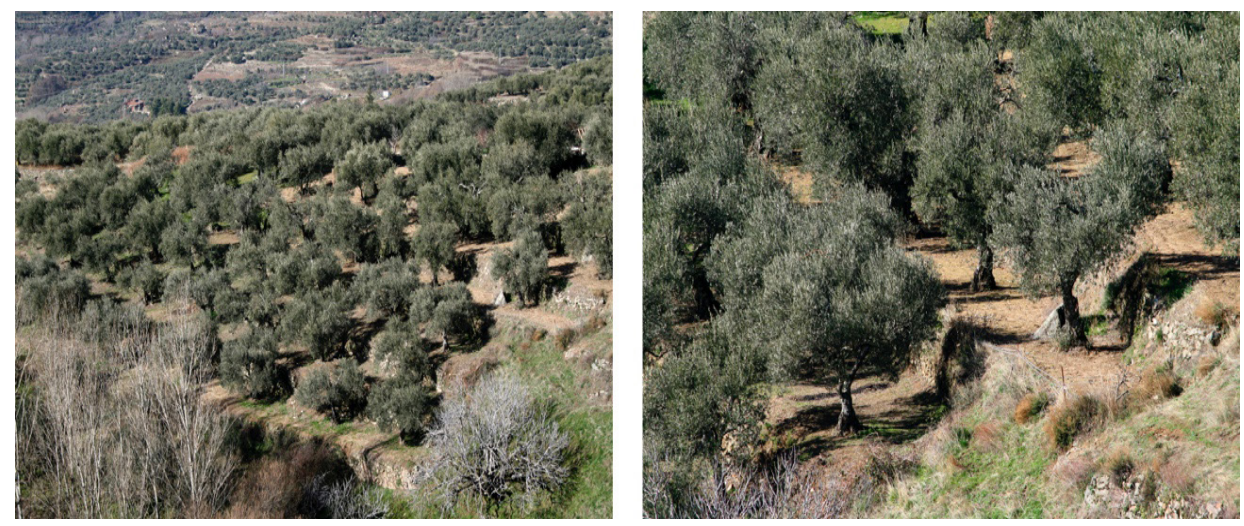

Figura 2. Bancales tipo «Valle del Tiétar» en San Esteban del Valle. Vista general (izquierda) y detalle (derecha). Fotografía: Autores.

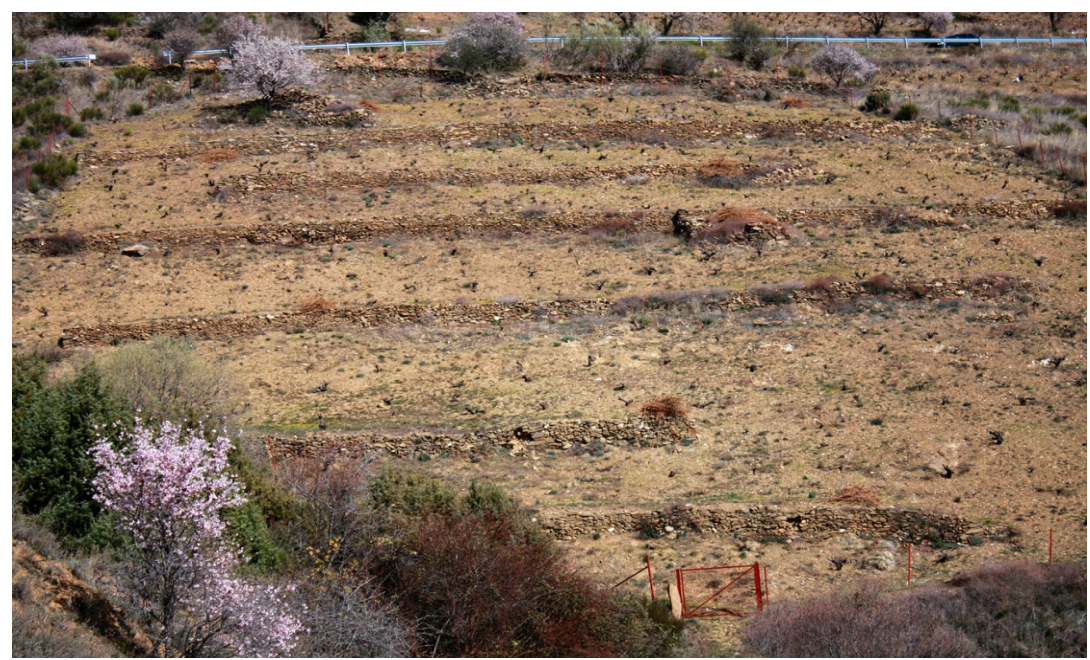

Figura 3. Bancales tipo «Cebreros» con viñedos de la denominación de origen. Fotografía: Autores. 
3) Bancales tipo «Peñalba de Ávila» (Figura 4). Son terrazas de tierra que no crean plataformas horizontales sino inclinadas, conservando prácticamente la pendiente natural. Su objetivo era acondicionar laderas para el cultivo de cereales (principalmente centeno) y también la retención de agua de escorrentía. Se trata de terrenos marginales de cultivo, sólo justificados en épocas de escasez de alimentos, como los años de la postguerra. El talud es de tierra, a modo de caballón, de pequeña altura (máximo $1 \mathrm{~m}$ ) y sin recubrimiento de piedras ni de vegetación. Actualmente se encuentran abandonados en la mayoría de las localizaciones, habiendo sido colonizados por herbáceas y matorral, y no presentan graves problemas de erosión. Los pastos se utilizan por la ganadería extensiva, generalmente de ovino. Aunque su ubicación se centra en las cuestas de Peñalba de Ávila, también aparecen, aunque en menor medida, en Monsalupe y Cardeñosa. En total hay unas 43 ha, de las cuales 37 ha se sitúan en Peñalba.

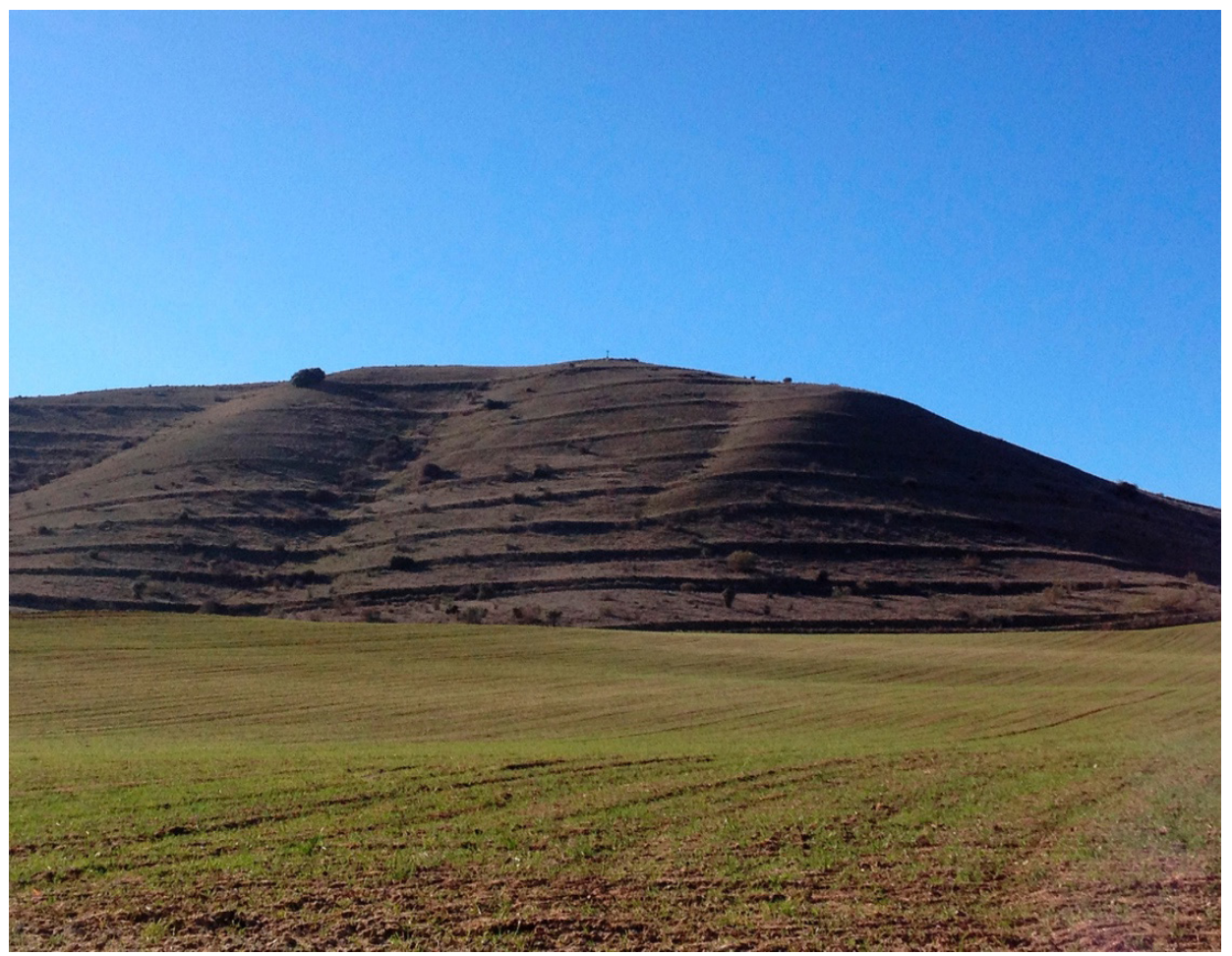

Figura 4. Bancales de tierra tipo «Peñalba de Ávila» en esta localidad. Fotografía: Autores. 
4) Gavias (Figura 5). Son un tipo de bancales que aparece en la comarca de El Barco de Ávila. Allí se establecen huertos y plantaciones de frutales en terrenos de pendientes suaves y, cada cierta distancia (varias decenas de metros normalmente), el desnivel se salva con un muro de piedra seca. Las gavias se riegan con agua procedente de acequias (regaderas), que generalmente forman una compleja red desde el río del que toman el agua. Por lo tanto, la función de la gavia es retener el agua de riego procedente de la regadera, fomentando su infiltración, por lo que guardan cierta relación con las gavias canarias (Perdomo, 2001), aunque bajo un clima notablemente diferente.

5) Bancales «individuales» (Figura 6). El «bancal individual» aparece en terrenos de pendientes fuertes, donde sólo pueden desarrollarse cultivos marginales poco productivos o pequeños huertos. Los taludes pueden estar sujetos por pequeños muros de piedra. Su objetivo es crear un área de cultivo de pequeña superficie, pero de notoria horizontalidad. Se han localizado en municipios tan distantes como Blascosancho (norte de la provincia) o Tórtoles (suroeste).

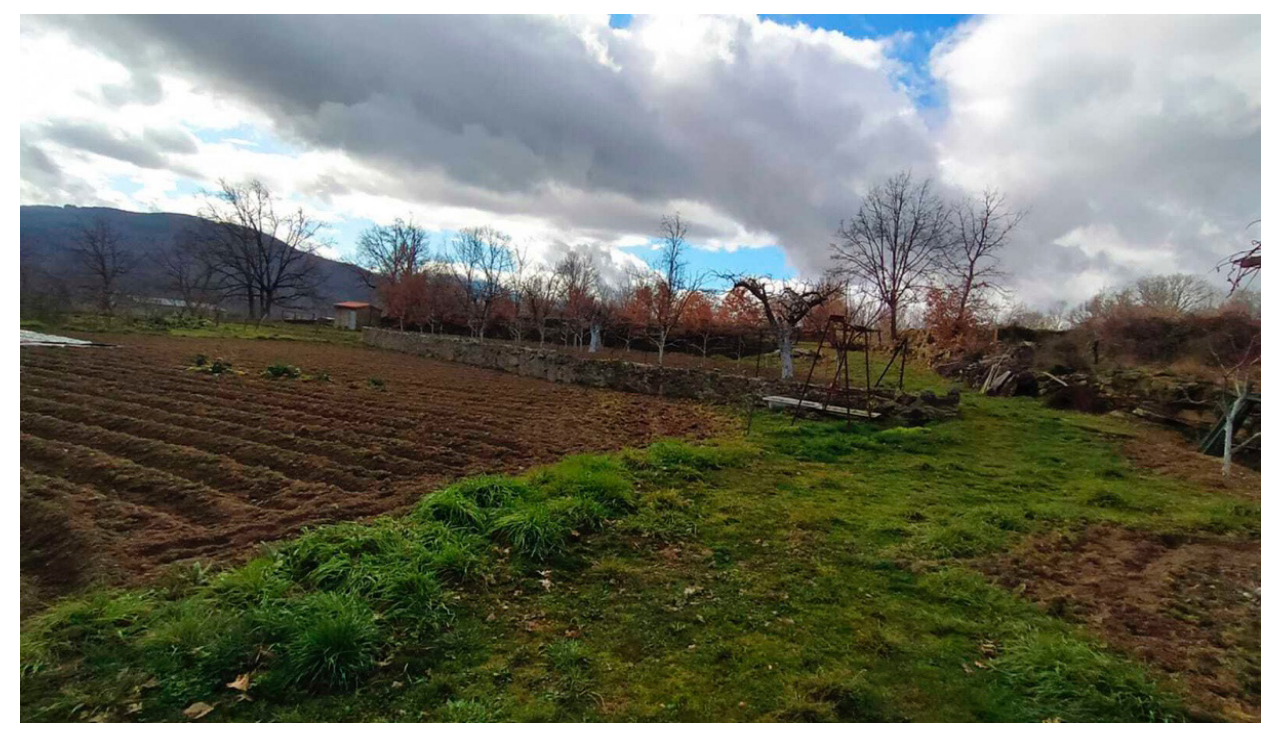

Figura 5. Gavia en La Carrera. Fotografía: Soraya Andaluz. 


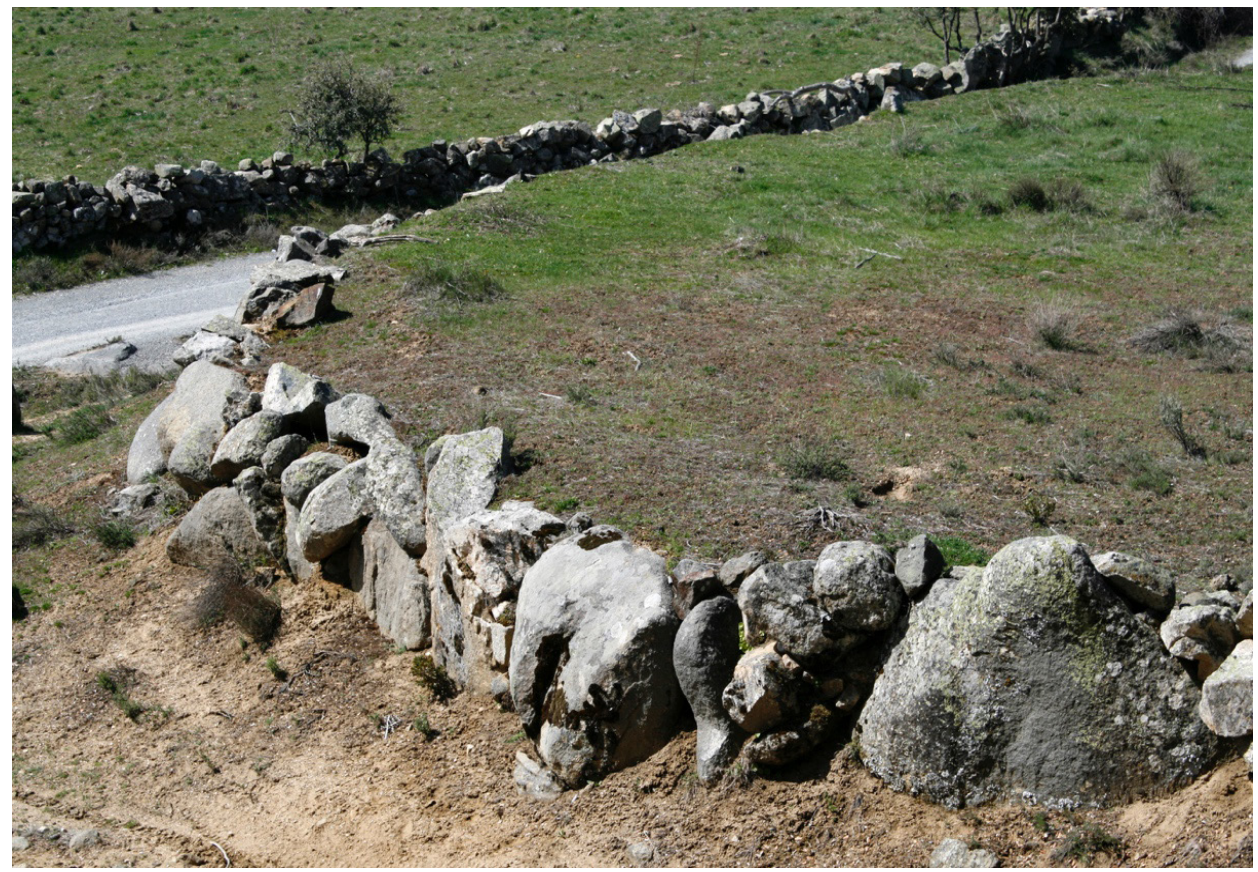

Figura 6. Bancal individual con muros de piedra seca en Tórtoles. Fotografía: Autores.

6) «Lindazos» o ribazos (Lámina 7). El sexto tipo es el denominado «lindazo». En la comarca de La Moraña, se emplea el término lindazo para referirse a algo similar al talud de un bancal, cuyo nombre más correcto sería ribazo, es decir, un talud o caballón de mayor o menor altura (habitualmente inferior a $1 \mathrm{~m}$ ), por lo general cubierto de vegetación natural, herbácea o de matorral, entre dos porciones de terreno de cultivo que están situadas a distinto nivel, y que sirve principalmente para mantener la horizontalidad (o pendiente menor de la natural) de las parcelas y así facilitar las labores, y en algunos casos, manejar el agua de escorrentía o de riego. El cultivo que se desarrolla entre lindazos es de cereales de secano, fundamentalmente trigo y cebada. La diferencia con el anterior tipo, además de tener una superficie mucho mayor, es la contar con menor pendiente en las laderas y la mayor distancia entre los sucesivos taludes (varias decenas de metros), que hace que el paisaje no se perciba como escalonado sino como una serie de parcelas de cultivo separadas por taludes de vegetación natural. 
Clasificación y caracterización de los bancales de la provincia de Ávila

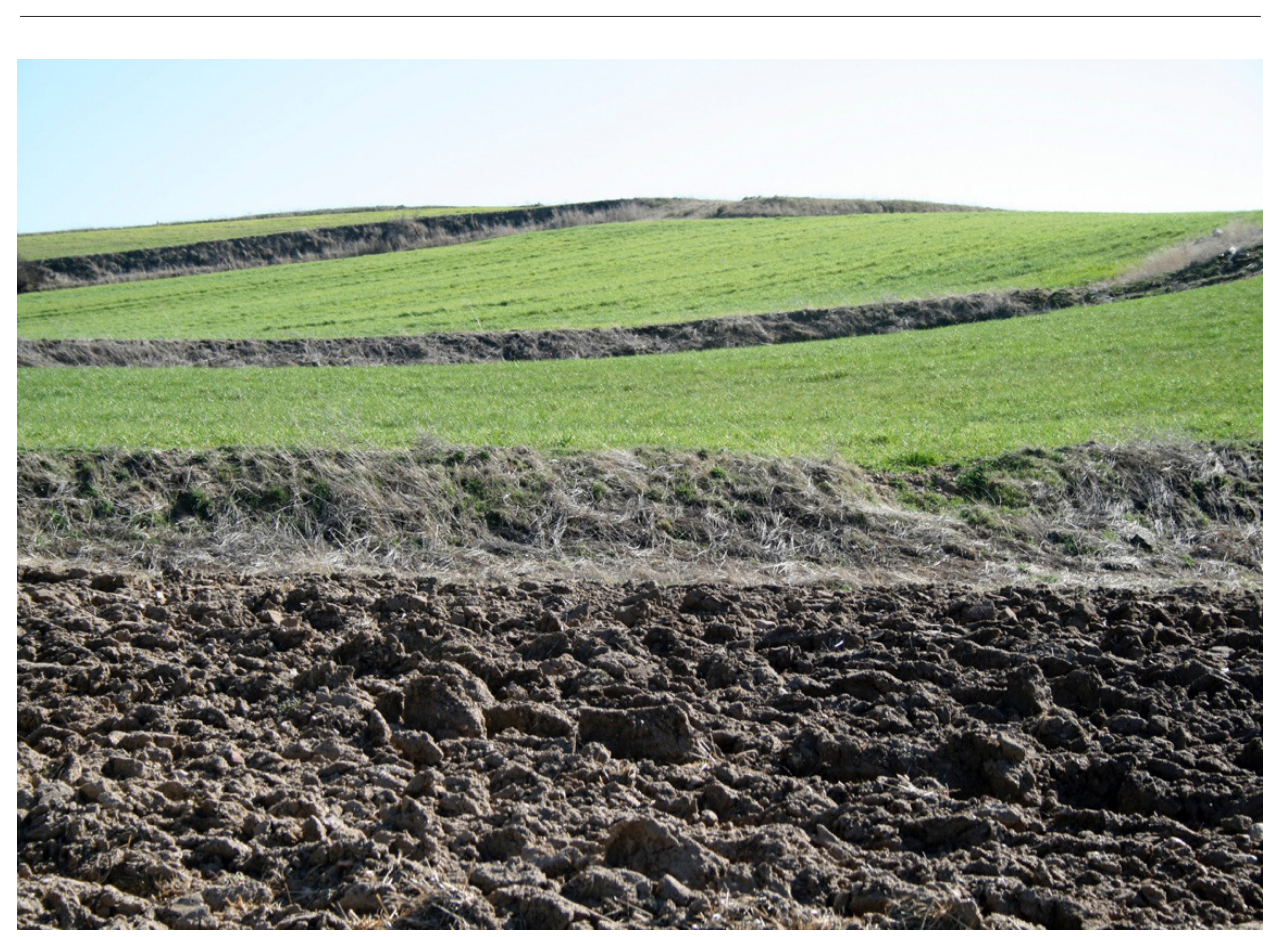

Figura 7. Lindazos o ribazos en Mingorría. Fotografía: Autores.

TABla 2

Caracterización de las terrazas y bancales presentes en la provincia de Ávila

\begin{tabular}{|c|c|c|c|c|c|c|}
\hline \multirow{2}{*}{ Caraterísticas } & \multirow[b]{2}{*}{ Tiétar } & \multicolumn{5}{|l|}{ TIPOS } \\
\hline & & Cebreros & Peñalba & Gavias & Lindazo & Individual \\
\hline $\begin{array}{l}\text { Anchura del } \\
\text { bancal }^{1}\end{array}$ & $\begin{array}{l}\text { Medio } \\
(5 \mathrm{~m})\end{array}$ & Medio (5 m) & $\begin{array}{l}\text { Medio a } \\
\text { ancho } \\
(5-10 \mathrm{~m})\end{array}$ & $\begin{array}{l}\text { Ancho } \\
(>10 \mathrm{~m})\end{array}$ & $\begin{array}{l}\text { Ancho (10- } \\
50 \mathrm{~m})\end{array}$ & $\begin{array}{l}\text { Ancho (10- } \\
50 \mathrm{~m})\end{array}$ \\
\hline $\begin{array}{l}\text { Pendiente del } \\
\text { bancal }^{2}\end{array}$ & Horizontal & En pendiente & $\begin{array}{c}\text { En } \\
\text { pendiente }\end{array}$ & $\begin{array}{l}\text { Pendiente } \\
\text { suave }\end{array}$ & $\begin{array}{c}\text { En } \\
\text { pendiente } \\
u \\
\text { horizontal }\end{array}$ & $\begin{array}{c}\text { En } \\
\text { pendiente } \\
u \\
\text { horizontal }\end{array}$ \\
\hline $\begin{array}{l}\text { Material del } \\
\text { balate }^{3}\end{array}$ & Piedra seca & Piedra seca & Tierra & $\begin{array}{l}\text { Piedra } \\
\text { seca }\end{array}$ & $\begin{array}{c}\text { Tierra con } \\
\text { vegetación } \\
\text { natural }\end{array}$ & $\begin{array}{c}\text { Tierra con } \\
\text { vegetación } \\
\text { natural } \\
\text { o piedra } \\
\text { seca }\end{array}$ \\
\hline $\begin{array}{l}\text { Altura del } \\
\text { balate }^{4}\end{array}$ & $1-2 \mathrm{~m}$ & $<1 \mathrm{~m}$ & $\leq 1 \mathrm{~m}$ & $1-2 m$ & $<1 \mathrm{~m}$ & $<1 \mathrm{~m}$ \\
\hline Sangrador $^{5}$ & No & No & No & Sí & No & No \\
\hline
\end{tabular}


Jorge Mongil Manso, Joaquín Navarro Hevia y José Carlos Sanz Belloso

\begin{tabular}{|l|c|c|c|c|c|c|}
\hline Uso $^{6}$ & $\begin{array}{c}\text { Olivos, } \\
\text { vides, } \\
\text { higueras, } \\
\text { otros frutales }\end{array}$ & $\begin{array}{c}\text { Vides, olivos, } \\
\text { pastos }\end{array}$ & Cereales & $\begin{array}{c}\text { Frutales, } \\
\text { huertos }\end{array}$ & Cereales & $\begin{array}{c}\text { Cereales, } \\
\text { huertos }\end{array}$ \\
\hline $\begin{array}{l}\text { Situación } \\
\text { actual }\end{array}$ & En uso & $\begin{array}{c}\text { En uso, } \\
\text { abandono }\end{array}$ & $\begin{array}{c}\text { Abandono, } \\
\text { pastizales }\end{array}$ & En uso & En uso & $\begin{array}{c}\text { En uso o } \\
\text { abandono }\end{array}$ \\
\hline Observaciones & $\begin{array}{c}\text { Extensas } \\
\text { áreas } \\
\text { abancaladas }\end{array}$ & $\begin{array}{c}\text { Continuos o } \\
\text { discontinuos }\end{array}$ & $\begin{array}{c}\text { Utilizados } \\
\text { en épocas } \\
\text { de escasez }\end{array}$ & $\begin{array}{c}\text { Se riegan } \\
\text { con } \\
\text { acequias }\end{array}$ & $\begin{array}{c}\text { El nombre } \\
\text { más } \\
\text { adecuado } \\
\text { sería } \\
\text { ribazo }\end{array}$ & $\begin{array}{c}\text { Poco } \\
\text { frecuentes }\end{array}$ \\
\hline
\end{tabular}

1. Anchura del bancal: Ancho, medio o estrecho (anchura aproximada en metros). 2. Pendiente del bancal (plataforma): Horizontal, en pendiente o en contrapendiente. 3. Material del balate: Mampostería, tierra o revegetado. 4. Altura del balate: en metros. 5. Sangrador: Si o no (con o sin sangrador o vertedero). 6. Uso: Tipo de cultivo. Fuente: Elaboración propia.

\section{CONCLUSIONES}

Los bancales tradicionales de la provincia de Ávila constituyen un agrosistema tradicional con diferentes funciones (productiva, cultural, paisajística, ambiental, turística, científica, etc.). Se distribuyen principalmente en las comarcas del Valle del Tiétar y en la del Valle del Alberche y Pinares, en este último caso asociados a la producción vitivinícola tradicional.

Pueden clasificarse en seis grupos, diferenciados por sus dimensiones, características constructivas, materiales empleados en su construcción, así como en los tipos de cultivos que soportan. Las terrazas del valle del Tiétar -las más representativas- son terrazas de banco o bancales, de absorción, de base media, construidas a nivel y con taludes de piedra.

Por sus funciones y valores, y por su carácter de patrimonio histórico, es necesario profundizar en el conocimiento de las terrazas abulenses y en sus potencialidades futuras, así como en todas aquellas acciones que frenen su degradación y permitan su conservación estructural y funcional.

\section{AGRADECIMIENTOS}

Este trabajo se incluye en el proyecto de investigación titulado «Los bancales de la provincia de Ávila. Un patrimonio rural tradicional a conservar», financiado por la Institución Gran Duque de Alba, de la Diputación de Ávila. 


\section{REFERENCIAS}

AsINS-Velis, S. (2006): «Linking historical Mediterranean terraces with water catchment, harvesting and distribution structures», en J.-P. MOREL, J. Tresseraas y J.C. Matamala (eds.), The archaeology of crop fields and gardens, Edipuglia, Bari: 21-40.

BALMASEDA, L.J. (2005): «La época visigoda», en M. MARINÉ (coord.), La historia de Ávila. I. Prehistoria e historia antigua, Institución Gran Duque de Alba de la Excma. Diputación de Ávila, Caja de Ahorros de Ávila, Ávila: 229-365.

Grove, A.T.; RACKHAM, O. (2001): The nature of mediterranean Europe: an ecological history, Yale University Press, New Haven.

López Cadenas, F. (2003): La ingeniería en los procesos de desertificación, MundiPrensa, Tragsa, Madrid.

Lasanta, T.; Arnáez, J.; Ruiz-Flaño, P.; Lana-Renault, N. (2013): «Los bancales en las montañas españolas: un paisaje abandonado y un recurso potencial», Boletín de la Asociación de Geógrafos Españoles, 63: 301-322.

Lasanta, T.; Arnáez, J.; Ruiz-Flaño, P.; Ortigosa, L. (2011): «Los bancales en la montaña mediterránea. Un paisaje multifuncional en proceso de degradación», en F. LeCo BerRoCAL (coord.), Territorio, paisaje y patrimonio rural, Universidad de Extremadura, Cáceres: 198-209.

LOURENÇO, L.; NAVE, A. (2007): «O papel dos socalcos na prevençao des incendios florestais. Exemplos das bacias hidrográficas dos ríos Ava e Alvoco (Serras do açor e da Estrela)», en Actes de Les Jornades sobre terrasses i preneció de riscos naturals. Consell de Mallorca, projecte europeu TERRISC de la iniciativa comunitària INTERREG III B SUDOE, Consell de Mallorca, Mallorca: 203-211.

Mongil, J.; Navarro, J.; García-Armunia, M. (2015): Técnicas tradicionales de captación y uso del agua. El conocimiento tradicional como base para la innovación, Universidad Católica de Ávila, Ávila.

NoRIYUKI, J. (2015): «Comparación de la política de terrazas entre Perú y Japón», en T. Tillmann y M. Bueno de Mezquita (eds.), il Congreso Internacional de Terrazas. Encuentro de culturas y saberes de terrazas del mundo, Cuzco: 38-48.

Perdomo, A.C. (2001): «El agrosistema de "gavias" de Fuerteventura (Canarias): un ejemplo de gestión ecológica del agua en zonas áridas en proceso de abandono», en V Jornadas Técnicas de la Sociedad Española de Agricultura Ecológica: el agua y la agricultura, gestión ecológica de un recurso crítico, SEAE, Mallorca.

Romero, L. (2015): Consecuencias geomorfológicas del abandono agrícola en la cuenca del Guiniguada (Gran Canaria, Islas Canarias): Aplicación a la conservación del patrimonio de bancales, Tesis doctoral, Universidad de Las Palmas de Gran Canaria, Las Palmas de Gran Canaria.

Romero, L.; Ruiz-Flaño, P.; Hernández, L. (2004): «Diagnósticos de calidad para la conservación de espacios agrícolas abancalados. Propuesta metodológica para la cuenca del Guiniguada (Gran Canaria, Islas Canarias)», Geographicalia, 45: 113-127.

Romero, L.; Ruiz, P.; Máyer, P.; Pérez-Chacón, E.; Hernández, L. (2006): 
«Recuperación de bancales: un ensayo metodológico en la cuenca del Guiniguada (Gran Canaria, Islas Canarias)», en A. Pérez y J. López (eds), Geomorfología y Territorio. Actas IX Reunión Nacional de Geomorfología, Santiago de Compostela: 933-943.

Romero, L.E.; GonZÁleZ, A.; RAMÓn, A. (2016): «Towards a new valuation of cultural terraced landscapes: the heritage of terraces in the Canary Islands (Spain)», ANNALES. Annals for Istrian and Mediterranean Studies, Series Historia et Sociología, 26 (3): 499-510.

SCARAmellini, G. (2005): «Il paesaggio agrario e il paesaggio culturale dei terrazzamenti artificiali nelle Alpi», en D. TRISchITTA (ed.), Il paesaggio terrazzato. Un patrimonio geográfico, antropológico, architettonico, agrario, ambientale, Città del Sole Edizioni, Reggio Calabria: 101-141.

Tarolli, P., Preti, F. y Romano, N. (2014): «Terraced landscapes: From an old best practice to a potential hazard for soil degradation due to land abandonment», Anthropocene, 6: 10-25. https://doi.org/10.1016/j.ancene.2014.03.002.

VARotTo, M. (2015): «Terraced landscapes of the Alps: Decay, rediscovery, revitalization», en T. Tillmann y M. Bueno De MezQuita (eds.), II Congreso Internacional de Terrazas. Encuentro de culturas y saberes de terrazas del mundo, Cuzco: $38-48$. 
